\title{
WISDOM AND HARMONY
}

\section{Introduction:}

Wisdom is a rather complex notion. The same can be said about harmony. Still both can be clarified a lot by interrelating them, as a true implicit definition. In fact a very promising approach to wisdom can be made by describing wisdom as multi-layered, dynamic, harmonic processes. These processes are the following ones.

1. Dynamic harmony of theory and practice.

2. Dynamic harmony between input and output processes.

3. Dynamic harmony between input and output processes: use of tools, language and communication for development of oneself, groups and environment, taking into view the danger of alienation through these tools.

4. Dynamic harmony between individual, group and environmental development in the several layers of competences and the integration in the several groups and ecosystems one belongs to.

5. Dynamic harmony between cooperative and protective behaviour mastering, surviving and control of the challenges of the hypocrites or dyssocials which disrupt the social environments and destruct its basic progress and growth in the individual as well as group lifecycles.

6. Dynamic harmony between brotherly behaviour processes and recognition processes of reciprocal brotherly behaviour and pseudobrotherly behaviour of dyssocials or hypocrites, development of skills for recognition of hypocrites or dyssocials and for individual and social defence, for isolating and even for reforming the hypocritical/dyssocials. Hypocrites/dyssocials are always returning to the offensive. The best is to develop wisdom for structural immunity against hypocrites/dyssocials. Even better is it to be able to transform dyssocials to constructive actors.

7. Dynamic harmony between the several main types of intelligences which as well on an individual level as on a group level are vital for sound growth and development.

8. Dynamic harmony between the different processes and roles of education and learning of the actors: children, students, adults, teachers, evaluators, pedagogues.

9. Dynamic harmony between the social interactions and especially the social media.

Let us very shortly comment the possibilities, challenges and perspective on each of these layers of dynamic harmonic processes characterising wisdom.

2. Some elaboration of the layers of the dynamic harmonic processes characterising wisdom.

2.1 The dynamic harmony between practice and theory.

Wisdom is always grounded in action, in practise in a specific environment. This environment can be defined, described, analysed in different ways. In "theory" development, one generalises the practical experience, the practice to more general environments. 
It is evident that the more generalised "know how", "know that", "know what", etc. has to be tested again and again, when it is being used in a new environment, whatever minimal the change in environment is.

This cyclic aspect of knowledge development and especially on the level of wisdom in knowledge, may never be forgotten or neglected. The practice, the applied dimension, the action is and has always to be the starting point and the ultimate target. Whatever the number of intermediary stages one also introduces, one may not forget this basic truism. Intermediary stages are between others testing, assessments, developing adequacy requirements, meta-theoretical features as aesthetics, statistical modelling, etc.

The danger is that too much attention is paid to this meta-theoretical level, neglecting the practical environment, the actors, the wellness and wellbeing of all these present at the end level. This danger is even worsened by the fact that theoretical activities receive in general higher social appreciation.

Here again one has to be aware of harmony between these several levels and processes of efforts, elaboration, in its very dynamic form.

\subsection{The dynamic harmony between input} and output processes (f.i. reading and writing)

The challenges are enormous. Each of us has to pay attention to his environment, to observe, to test, to try out, to read, to analyse, to understand, to theorise about our live, our work, about the solutions, the changes, the constructions and destructions which are going on...

As important as being open to listen, to look etc. to our environments, our colleagues, our enemies, our adversaries, we must also try to elaborate our own understanding, try to make syntheses, to formulate solutions, to try out new approaches, to explain it to others, to try to convince others: to talk and write about our own views, perspectives, futures, to construct our own future and our own environment.

However it is clear both processes of inputting and outputting, have to interact, to get harmonised: again and again. Harmonisation is not realised at once. Harmonisation is a continuous cyclic process, with always new challenges, new attempts, taking care in this continuous process of harmonisation, not to make deep and irrevocable destruction and chaos.

If nevertheless chaos is created, make sure that this is an isolated intermediary stage for realising higher level of harmony.

2.3 Dynamic harmony between processes of tool use, language use and communication use.

Wisdom has an important layer of communication processes. We can differentiate or rate the communication processes with or through tools, with or through language, with a through non language symbols... In and through this communication processes, we change ourselves, our relations and interrelations with the other actors and our physical, social and psychological worlds.

Again on each level: individual, social, environmental, we have to be aware of the necessity always to have and realise a minimal level of dynamic harmony between these several communication processes. We need always to get above a minimum dynamic threshold of harmony...

In self-education and education of children or adults or seniors or nestors, we have always to be aware of the danger of alienation. One 
way of communication form (f.i. tool use: computer games, computer use) can get autonomic. Instead of being one of so many other ways of communication, it can become a fetish, an enslaving, a compulsive dominant autonomous process.

If this happens, it leads only to destruction of the individual or the group where this type of communication process is started.

In education and learning in general we need to be anxious to avoid that tool use is triggered in an autonomous dominant isolated process.

Again only dynamic harmony between the several ways of communication can bring success, progress and wellbeing.

\subsection{Dynamic harmony between individual,} group and environmental development.

Wisdom requires that one considers ones actions and their consequences, taking into account the dynamic harmonious development of oneself: the individual. Still each individual is a part of several groups (e.g. family). Moreover each individual and each groups he/she belongs to are part of an ecological environment. The change to one of these building stones has repercussions on the others. This means that one has always to try to have in mind the harmonic development of each of these. The individual may not be sacrificed for the group, or for the development of the environment, nor vice versa.

Moreover one has to take care, to consider each of these constituents in view of their lifecycle. The role, the perspective, the care, etc. of f.i. an individual as a baby or as an adult or as a nestor in view of a dynamic harmonic development of the whole is fundamentally different.

\subsection{Dynamic harmony between coopera-} tive and protective behaviour in view of handling hypocrites or dyssocials.

In all cultures: historically or actually, we see that in their myths a lot of attention is paid to handle, to treat hypocrites or dyssocials. We find that back in the myths and stories of Mesopotamia, Egypt, Greece, Rome, in Indo European, American Indian, Islamic, Hebrew, Christian cultures, etc. ( F. Vandamme 2013).

This illustrates how important in ancient times, as well as in the present world, it is to handle hypocrites or dyssocials. In other words it is vital to find a dynamic harmony between cooperative behaviour and protective, defensive behaviour. Both types of behaviour are vital for survival. Nevertheless there is a necessity to have a dynamic harmonic equilibrium between protective, defensive behaviour at one side and the cooperative behaviour at the other side. Wisdom is characterised to an important degree by this harmonic equilibrium between both. Anyway handling hypocrites/ dyssocials is an ultimate challenge for and a characteristic layer of wisdom. Why is this the case? The answer is simple. Hypocrites, also called dyssocials are individuals (sometimes groups), which simulate very kind friendly, social behaviour. This friendly social behaviour is a cover-up for attempts of destruction of other actors, groups or even cultures of their ideals, targets ...

They pretend to promote the others ideals, but in fact they try in a hidden fashion to make these targets impossible or even destruct their constructions. They tell that they want to promote peace (e.g.), why in fact they do their utmost to promote war, etc. Therefore technically hypocrites can be called "dyssocials" referring to the Greek term "dys", which means "difficult". They are therefore "difficult social pe- 
ople" that is contrary to what they look like. For this reason although wisdom is very crucial in cooperating with others, it is as crucial never to forget, to lose the protective, defensive dimensions of action. This is vital to avoid that cooperation is exploited by dyssocials or hypocrites to destruct the future of the intended cooperative targets.

\subsection{Dynamic harmony between brotherly behaviour processes and differentiating pro- cesses of brotherly behaviour and pseudo- brotherly behaviour of dyssocials or hypocri- tes.}

In social interaction, the brotherly behaviour in the many interpretations of this terms are important, for the strengthening of cooperation, wellbeing, wellness, for realising prosperity and progress. Still brotherly behaviour can very easily be abused. Wisdom requires that each brotherly process is combined with processes of recognising reciprocal brotherly behaviour. Hypocrites or dyssocials in their friendly cover-up, can pretend easily and very efficiently friendly behaviour. Still they are not able to realise, to have a brotherly behaviour. The differentiation between brotherly behaviour and pseudo-brotherly behaviour is a very important skill and know-how deeply imbedded in humans and even in animals.

This means that a dynamic harmony is crucial too, between brotherly behaviour and recognition processes for brotherly behaviour. In fact an integrating part of brotherly behaviour is the target $\mathbf{2}$ to learn others genuine brotherly behaviour. This type of brotherly behaviour is only possible when one is able to recognize pseudo-brotherly behaviour.

2.7 The dynamic harmony between the several main types of intelligences
There are a lot of different types of intelligences. The dynamic harmonic integration and use of the different types of intelligences is crucial for wisdom. A short characterisation of these several types of intelligences follows.

\section{Caring intelligence}

First, we pay attention to the "caring intelligence". This is effectively a very important intelligence in very many phases of development. The caring intelligence is the basis for trust in each other, for feeling of security. Hence it is a basis for self-confidence and willingness to open up to others, for the future.

The caring intelligence includes attention for the other, for the environment, for the needs of each, in the short time, but also in the long time. It includes not only attention, perception, and feeling but also action and looking ahead to what needs to be completed, or how things develop. Foresee possible dangers and threats. Focus again and again on anything and everything with unlimited willingness to take action... Caring intelligence is an ongoing challenge...

\section{Rational intelligence}

Another, but more supportive intelligence is the "rational intelligence". It is rooted in the emotions and the emotional intelligence. In addition it causes a lot of emotions... Yet, rational intelligence is an important factor in support and maintenance, as long as it is not too dominant or at least not too long dominant. After all, rational intelligence without embedding in emotional and other intelligences is dead, sterile. This becomes clear when we understand the rational intelligence.

Rational intelligence deals with efficiency, economy and thrift in employing resources, means to achieve goals. In other words, it has to do with optimization when using resources. The 
choice of the goals, targets as well as the acceptability of the chosen means, are beyond the rationality, are provided by the many other intelligences.

Rationality is important, to the extent that economy or thrift and efficiency to achieve goals with present acceptable means, does have relevance for the stability and safe growth and development of the partners, stakeholders (family in the narrow and broad sense) and their environment.

\section{Action intelligence}

The action intelligence is related to rituals. Ritualization is crucial to uplift action and experience above arbitrariness and chance. Rites are filters that purify actions without letting them degenerate into absolute norms, standards or essences.

The ritualization of action leads on the one side to generalization. On the other side by confronting actions with other actors, we get interiorisation but also objectification and more explicitness. This has an impact on internal physiccal, psychological and emotional forces and processes. Action and especially its ritualization is thus the way par excellence for better harmonious development, living together, for individual and collective well-being and tranquillity.

\section{Energetic intelligence}

The energetic intelligence is the basis of life. Both at the micro level for monitoring, controlling the major energetic power flow, as well as at the macro level, in order to sustain life and regenerate it, the energetic intelligences are fundamental. These energetic intelligences are whether or not cyclic, whether or not periodical. They are interactive. They are sometimes symbolically represented by the four elements (better known as the four basic energetic processes): fire, wind, water and earth. These energetic intelligences also constitute the core of processes, interactive with the other intelligences in their many forms.

This energetic intelligence is in some approaches to culture extensively treated and described. In contemporary Western approaches, relatively little attention is paid to the energetic intelligence, except from a limited information technical perspective... However we should first of all be attentive for the complex processes of energy within the individual and his integration, interaction and involvement of many individual energetic processes of energetic intelligence within the complex cultural-energetic intelligences of the group. More specifically, it is important to pay attention how the macro-energetic intelligence can stimulate and/or break the individual energetic complexes. How they lead to collective and individual energetic intelligent prosperity or on the contrary to mortification.

We see frequently how in complex macro energetic conglomerations, local deployment, expansion and self-sacrifice are generated to enable global harmony and progress. This then has an impact on the development and shaping of the other types of intelligences.

This is not only true for humans but also for many other species of animals, mammals, as well as insects, birds...

We like to further examine this matter, considering its fundamental importance. Very striking and important is that a person sometimes is humbly active in the background. However, if for some reason in the culture, organization of the group he/she becomes responsible, we see that he/she will emerge as a highly intelligent leader with insight and efficiency. The energetic macro process can lead to above normal intelligence and efficiency. Others, however, are brought to sub-intelligence, to be- 
come rather passive actors, followers, who make the overall survival and the growth of the community possible. Of course, this may be accompanied by differentiation and specialization. One can be very actively and intelligently busy in certain phases, tasks and become a blind follower in other tasks/phases... This energetic intelligence can lead to conflict reduction and strengthen creation of unity/harmony which may be a prerequisite for local or global creativity and improvisation ... at least temporarily...

In many cultures, religions, the energetic intelligence is associated with the holy, the sacred: the sacrum: sacral bone or tail bone (the bone consists of the union of the five vertebrae of the lower part of the spine).

According to some, the sacral bone is so named, because that part of the animal sacrifice was offered to the spirits. Another way to say the same thing probably is that this portion of the skeleton protects the genital organs of male and female: the egg and sperm. This sacral bone has the suggestive shape of a dagger. It has also the shape of the tree of life. It is a symbol of immortality, resurrection, recreation, energy (Buddhist, Arabic "Aldabara", Hebrew LUZ: that is what is hidden, i.e. the core, the seed. It also refers to the light).

The base of the spine, the sacrum, symbollized for example by the evergreen pine, decorated and enhanced with light, supports, complements and strengthens the power of the sun. It participates and contributes to the divine in the many senses and meanings of the word.

\section{Emotional Intelligence}

Emotional intelligence is a very important intelligence. It determines the first and fastest response, reaction to external and internal inputs, influences on both external and internal developments and dysfunctions. Emotional in- telligence is a first positive as well as negative "warning system" on events. It is therefore a first reactor and contributor to and for balanced internal or external integration of forces and interactivities. Emotional intelligence is frequently symbolized by the "stomach", even though it is usually a total physical expression, perception, and detection and signal system. Besides stomach reaction, sweating, vomiting, etc. are signals from the emotional intelligence.

As both a positive and negative warning system, emotional intelligence can inhibit processes, strengthen, slower, accelerate, increase or decrease the attraction or repulsion...

Also for therapeutic interventions as well as for the correcting of partial, total or global dysfunctions, emotional intelligence has an important role.

\section{Sexual intelligence}

The symbol for sexual intelligence is the skin: the largest organ of the body. Central to the skin is the feeling, the sensory pleasure arisen from and targeting the sexual pleasures in a weaker or a stronger degree. For the sexual intelligence the other senses are important too: sight, hearing, taste. The orgasm is here an element, a phase. Certainly it is not the goal, certainly not the only goal. Sexual intelligence uses the different types of physical feelings, sensations, and expected sensations, seasoned with the other forms of type of intelligence.

Not only do we have a very large variety of possible physical sensations. Also, the place of the body that is approached, that is treated is important. Even though it is true that the 'alpha and omega', or 'dildum and yoni', or put another way, 'the penis and vagina' or their equivalents 'flower and stamen' can / will play an important role at certain moments in certain phases. Equally important in sexual intelligence is 
the ability to give, but also to receive feelings, sensations in the broad perspectives of the processes. Managing to dose the surrender to feelings, but also to maximize them in function of the collective unity, harmony, transcendent unification in its multiple forms of intelligence and symbols, is one of the challenges of the sexual intelligence.

\section{Storing intelligence}

This intelligence concerns persistence, maintaining reserves, making the bridge between past, present and future. The storing, protective intelligence is vital for both micro and macro systems. The wealth, the luxury, the price of what is saved is not so important. Much more important is their value, their relevance for the existing, the relevance as a testimony of the past. The storing intelligence is also crucial for the continuity, appreciation, relevance, concern for the present with an eye also for a secure future with expansion and growth. No expansion and growth for the growth itself! This is indeed destructive. Also no growth for pseudo splendour, pride or deliberate self-destruction! That is why preservation and storing intelligence, although this should never be a goal in itself, should, is and remains very important.

\section{Transcendent intelligence}

The transcendent and the integrating intelligences are for action, for wellness, well-being and living together the most important intelligences. Usually, however, one takes into account all other types of intelligences except the two above-mentioned. Yet, take transcenddent intelligence. This is so important in all processes where one transcends oneself and his group, for the sake of the utility, the good, the future of the other individuals and the group. Sacrifice, self-transcending, self-development for the other, the others, the universe for all that one appreciates and loves is obvious for each actor. We are as individuals and as a group capable out of through estimation, love... to make incredible efforts and actions of sacrifice and self-transcendence

The transcendent intelligence is the intelligence that allows to transcend the immediate in time and space to a more general, more timeless and more space less target and quality. The transcendent intelligence is a purifying intelligence. This transcendence may take many forms but remains aware of the world here and now. The self-protection while surrendering oneself to the transcendence is still important, how easily however even that it is overlooked.

Transcendence through its exceeding of the hic et nunc, the here and now, is the basis of creativity, for encouraging diversity, but most of all for unification over and through the diversity, transcending the day and the night, the action and the rest, the sun, the moon and the stars. Transcendent intelligence encourages, nourishes, points at and harmonizes with the other forms of intelligence. The transcendent intelligence gives expression to the knowing that 'together', the knowing how 'together', the feeling 'together', the learning 'together', wanting 'together', doing 'together' ... in short, of connecting 'together' in beauty, strength and unity...

\section{The integrating intelligence}

Along with the transcendent intelligence is integrating intelligence the most important of all intelligences. Creativity, strategy, self-development, self-sacrifice, compassion, understandding, analysis, labour, suffering, happens for the sake of integration, harmony, unity. The integrating intelligence is the intelligence whereby synthesis, integration, harmony can be created. If this integrating intelligence is not dyna- 
mic, it is dead. These processes are always in movement, always evolving, yet always improveing in vitality, in depth, in level. Harmony, synthesis, integration of the first, second and nth level, in theory and in practice.

The harmonizing and integrating intelligence has to do with the Art to recover and improve quality and quantity of harmony. This requires important, intense interaction and action at every level, at any place, at any time, in any dimension in this globally harmonizing and unifying perspective, without losing sight of the diversity and local uniqueness, growth, dynamics and evolution. It even stimulates them.

\subsection{The dynamic harmonic integration of different types of education and learning roles as a basic challenge of wisdom.}

Each individual has different roles. In the education learning process continuously, we have simultaneous the role of "child", of an "educator", "a teacher", "an assessor", "a controller of the educative processes"," a certification processor", "an analyst" , "a researcher of education and learning", etc. It is crucial that we very consciously execute several of these roles. By executing and fulfilling these several roles we need to ameliorate our understanding and performance of these task and underlying processes. At the same time, we have to take care that these several roles develop in a dynamic harmony.

2.9 The dynamic harmonising of the direct social interaction, and the technical supported social media.

The last ten years we have an important progress and growth concerning the technical supports for social interaction through internet and the social media. These last are perhaps even more and more a danger for normal social interaction. For sure, technical support for so- cial interaction is already very old. We find it already within the oldest forms of civilization (cfr. Stonehenge). Still never before has the danger of dominance of the technical supported social interaction with its external control and guidance, and commercial exploitation been that influential.

This means that the challenge of the dynamic harmonisation of normal social interaction and technical supported social interaction is that difficult and therefore so crucial for the realisation and progress of wisdom.

\section{Conclusion}

Wisdom has always been very important for surviving and creating, protecting and safeguarding happiness, wellbeing and most importantly humane societies and lifestyles. Today however the challenges and threats are enormous. The number of people on this planet earth is very fast growing. We are depleting, destructing our stocks and supplies. Moreover by our wars and clashes of ideas, ideals, targets and cultural and economic divergences we are very fast destructing our ecological environments. One of the dominant technologic cultures today is the Indo-European Culture. In the Indo-European Culture we have a very dominant, strong anti-harmonic view with the strong destructive slogan:" Who is not with me, is against me".

This is fundamentally in opposition to the view in favour of dynamic harmonic development. Nevertheless only Wisdom with its multiple layers of search and targeting dynamic harmony, can help us to find and create a future for humanity and for most of the ecological systems. 


\section{REFERENCES}

1. Kaczmarsky P., et al. (2014). "Social Media and Education. Dangers and Promises: a call for Cooperation". Communication \& Cognition, Vol XLVIII, N ${ }^{\circ} 1-4$.

2. Muylle, F. (2014). Point of view. Part 1: Introduction and challenges (Social media and education. Dangers and promises: a call for cooperation). Retrieved from: http://www.lotuswebtec.com/en/compon ent/content/article/88-gnostotheek-category/servicescategoty/257standpuntensept.html

3. Muylle, F. (2014). Point of view. Part 2: Basic questions, which have to be formulated! (Social media and education. Dangers and promises: a call for cooperation). Retrieved from: http://www.lotuswebtec.com/en/component/content/article/88gnostotheek-category/services-categoty/257-standpunten-sept.html

4. Muylle, F. (2014). Point of view. Part 3: Some basic research answers and research questions. (Social media and education. Dangers and promises: a call for cooperation). Retrieved from: http://www.lotuswebtec.com/en/component/content/articl e/88-gnostotheek-category/services-categoty/257-standpunten-sept.html

5. Muylle, F. (2014). Point of view. Part 4: Conclusions. (Social media and education. Dangers and promises: a call for cooperation). Retrieved from: http://www.lotuswebtec.com/en/component/content/articl e/88-gnostotheek-category/services-categoty/257-standpunten-sept.html

6. Muylle, F. (2014). Punto de vista. Parte 1: Introducción y desafíos. (Redes sociales y educación. Peligros y promesas: una llama- da a la cooperación). Retrievedfrom: http: //www.lotuswebtec.com/es/component/c ontent/article/88-gnostotheek-category/se rvices-categoty/257-standpunten-sept.htm I

7. Muylle, F. (2014). Punto de vista. Parte 2: Preguntas básicas, ique tienen que ser formuladas!. (Redes sociales y educación. Peligros y promesas: una llamada a la cooperación). Retrieved from: http://www.lotus webtec.com/es/component/content/articl e/88-gnostotheek-category/servicescategoty/257-standpunten-sept.html

8. Muylle, F. (2014). Punto de vista. Parte 3: Algunas respuestas de investigación básicay las preguntas de investigación. (Redes sociales y educación. Peligros y promesas: una llamada a la cooperación). Retrieved from: http://www.lotuswebtec.com/es/component/content/article/88-gnostothe ek-category/services-categoty/257-standp unten-sept.html

9. Muylle, F. (2014). Punto de vista. Parte 4: Conclusiones. (Redes sociales y educación. Peligros y promesas: una llamada a cooperación). Retrievedfrom: http://www.lotus webtec.com/es/component/content/arti cle/88-gnostotheek-category/services-ca tegoty/257-standpunten-sept.html

10. Rousseaux, M., Wang, L. \& Vandamme, F. (2013). Het leeractieteam Cupie-Do. Gent: Communication \&Cognition.

11. Vandamme, F., et al.(2013).Gnostology, http://www.lotuswebtec.com/en/2013-1204-10-59-23.html

12. Vandamme, F., et al. 2014. "Social Media and Education. Dangers and Promises: a call for Cooperation". Communication \& Cognition, Vol XLVIII, № 1-4. 
13. Vandamme, F.J. (2013). Het Ware Verhaal van Hiram. Phoenix collectie, Gent: $\underline{\text { Com- }}$ municatie \& Cognitie.
14. Wang, L., et al. (2009). Confucius sleutel naar de toekomst? Gent: Communication \& Cognition.

VANDAMME F., WANG L., ALBIÑANA D., DEBRAUWER A., KACZMARSKI P

\section{WISDOM AND HARMONY}

\section{SUMMARY}

Wisdom and harmony must be approached as multi-layered, dynamic processes. The learning action team focuses on supporting especially young people and elderly people in their challenges of integration and development. These differrent layers of wisdom and harmony are crucial motors for innovation and strengthening progress as well for practice, therapy and theory...
Key concepts: wisdom, education, dynamic harmony, theory, practice, input, output, tools, life cycle, language, communication, individual, group, cooperative, protective, dyssocials, types of intelligences, roles, social interactions, digital platforms, social media, hypocrite, nesters.

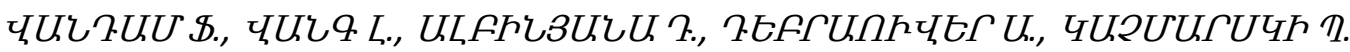

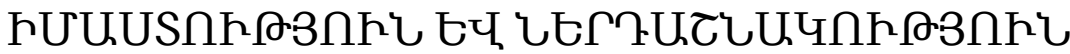

\section{UUФПФกЋU}

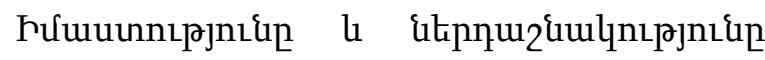

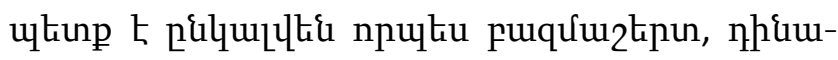

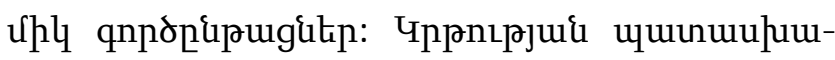

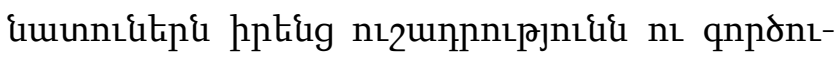

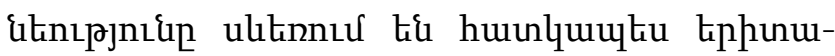

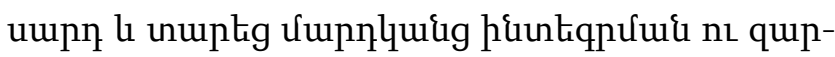

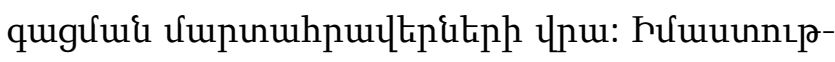

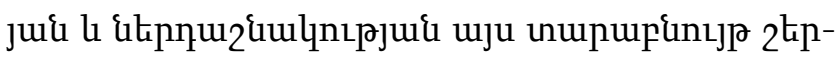

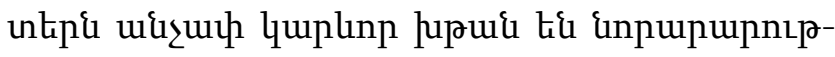

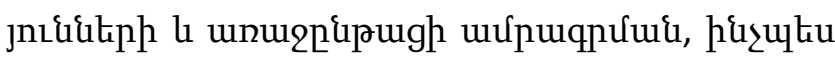

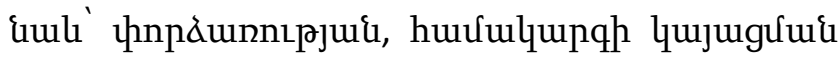

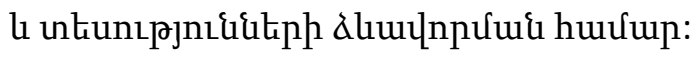

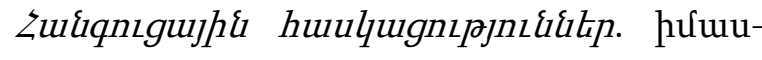

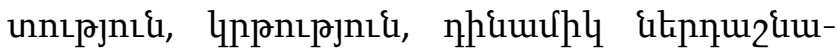

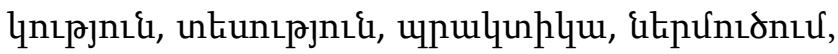

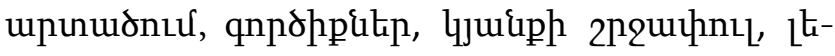

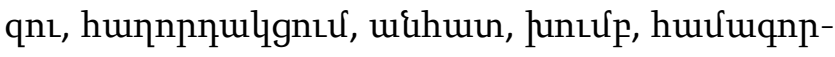

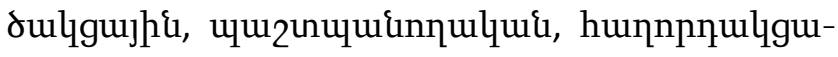

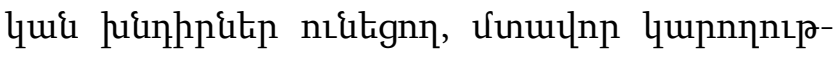

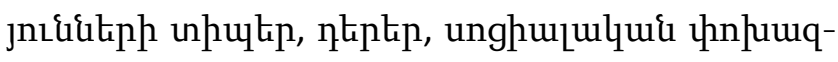

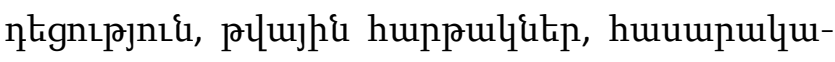

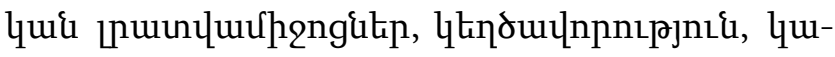
nnıgnๆ: 


\section{МУДРОСТЬ И ГАРМОНИЯ}

\section{PEЗЮME}

Мудрость и гармонию следует рассмотреть как многослойный, динамический процесс. Группа обучающей деятельности фокусирует внимание на поддержке молодёжи и пожилых людей при вызовах интеграции и развития. Эти различные слои мудрости и гармонии выступают как решающие двигатели инновации и усиления прогресса, а так же для практики, терапии и теории.
Ключевые понятия: мудрость, образование, динамическая гармония, теория, практика, включение, вывождение, инструменты, жизненный цикл, язык, коммуникация, индивид, группа, взаимодействующий, защитный, ущербный в плане общения, типы интеллекта, роля, социальная медия, лицемерность, строитель. 